\title{
THE STATE OF DEVELOPMENT OF WASTE FORMS FOR MIXED WASTES
}

\author{
Study performed by the Committee on Mixed Wastes of the Board on \\ Radioactive Waste Management, US National Research Council (1) \\ By Dr Paul Dejonghe, Committee Chair, retired from SCK.CEN, Mol, Belgium, \\ Em. Lecturer at the Catholic University of Leuven, Belgium; \\ Dr John R. Wiley, Senior Staff Officer, Board on Radioactive Waste Management, \\ US National Academies, Washington, D.C.
}

\begin{abstract}
More than $167,000 \mathrm{~m}^{3}$ of mixed waste, waste that contains both chemically hazardous and radioactive components, are in the known inventory at DOE sites that formarly produced nuclear defense materials. The inventory contains both mixed low level wastes (MLLW) and mixed transuranic wastes (MTRU). Site cleanup and decommissioning activities during the coming years are expected to nearly double this inventory. At the request of the DOE Assistant Secretary for Environmental Management (EM), the National Research Council's Board on Radioactive Waste Management (BRWM) appointed a Committee on Radioactive Mixed Wastes which issued its final report in June 1999. The main task of the committee was to review and evaluate the state of development of the final waste forms of treated mixed wastes as they arise from current and emerging treatment technologies. In particular, the study assessed the characteristics of, and uncertainties associated with, the different kinds of waste forms, and identified needs for additional R\&D.
\end{abstract}

The Committee's general finding is that the currently available waste forms are sufficiently developed to meet regulatory requirements for disposal of DOE's known and expected mixed waste inventory. No single form is appropriate for all wastes, but collectively the available waste forms and well established waste treatment technologies make it unlikely that a totally new class of waste forms will be necessary to complete EM's planned cleanup programme.

\section{INTRODUCTION}

More that 167,000 cubic meters of mixed waste, waste that contains both chemically hazardous and radioactive components, are in the known inventory at the U.S. Department of Energy (DOE) sites that formerly produced nuclear defense materials. The inventory includes both mixed low-level wastes (MLLW) and mixed transuranic wastes (MTRU) wastes. Site cleanup and decommissioning activities during the next several years are expected to nearly double this inventory, and the inventory will be further increased by mixed wastes retrieved as a result of DOE site remediation. Processing and permanent disposal of these mixed wastes is a part of the DOE Office of Environmental Management (EM) program to close former DOE production sites (2).

Within EM, the Office of Science and Technology (OST, EM-50) is charged with assuring that safe, cost-effective technologies are available for the entire closure program. To address mixed waste technology needs, OST established a special program and management team, the Mixed Waste Characterization, Treatment, and Disposal Focus Area (MWFA), in 
1994. At the request of OST, the National Research Council (NRC) convened a Committee on Mixed Waste to assess specific technical issues being addressed by the MWFA. A review of all OST technology development activities was completed in 1995 (3).

For the present task, the mixed waste committee was requested to review and evaluate the state of development of the final waste forms for disposal of mixed wastes as they arise from current and emerging treatment technologies. The review was also to identify the technology development options DOE might consider to achieve waste forms that are cost effective and safe for disposal.

Mixed waste management and disposal are complex technical and regulatory challenges. It is a technical challenge because of both the quantity and wide variety of mixed wastes within EM's responsibility (see tables 1 and 2). Examples range from small amounts of laboratory wastes that contain many chemicals and relatively high levels of radioactivity, to large volumes of soil and debris that contain only slightly contaminated material. Treatment technologies, therefore, must deal with a broad range of chemical and physical properties and volumes. Treatment objectives are generally to reduce the volume, to reduce the chemical hazards of a given waste material and to render it into a stable waste form.

Regulatory complexities arise because regulations have been developed by two different regulatory agencies that have taken two different approaches to protecting the environment. Regulations apply to handling, storing, transporting, and treating the waste, to characteristics of the waste form, and to the disposal facility. The U.S. Nuclear Regulatory Commission regulates waste form stability and radioactive characteristics of low-level waste materials acceptable for near-surface land disposal through a combination of prescriptive- and performance- based requirements. DOE orders meet or extend the regulatory criteria established by the USNRC. The U.S. Environmental Protection Agency (EPA) has authority to regulate hazardous waste, which includes discarded materials that are corrosive, ignitable, reactive or contain toxic compounds. 
Table 1. Hazardous Characteristics as a Percent of the EM Mixed Waste Inventory (4)

\begin{tabular}{|l|l|}
\hline Hazardous Characteristics & Percent of Inventory Volume \\
\hline Ignitable & 22 \\
Corrosive & 21 \\
Reactive & 7 \\
Toxic Chemicals & 59 \\
Heavy Metals & 58 \\
Mercury & 26 \\
Lead & 54 \\
Chromium & 31 \\
Cadmium & 27 \\
Organics & 30 \\
Solvents & 82 \\
Electroplating Waste & 64 \\
Cyanide & 34 \\
Leachate Treatment & 15 \\
Non-specific Listed Contamination & 11 \\
\hline
\end{tabular}

Table 2. Treatment Groups for EM Mixed Waste (5)

\begin{tabular}{|l|c|c|c|c|}
\hline Waste Group & $\begin{array}{l}\text { Percent of EM } \\
\text { Inventory }\end{array}$ & $\begin{array}{l}\text { Percent to be } \\
\text { Treated in an } \\
\text { Existing DOE } \\
\text { Facility }\end{array}$ & $\begin{array}{l}\text { Percent to be } \\
\text { Treated via } \\
\text { Private Contract }\end{array}$ & $\begin{array}{l}\text { Percent } \\
\text { Unassigned }\end{array}$ \\
\hline Waste water & 4 & 2 & & 2 \\
$\begin{array}{l}\text { Combustible } \\
\text { Organics }\end{array}$ & 1 & 1 & 7 & 38 \\
$\begin{array}{l}\text { Inorganic, } \\
\text { Homogeneous } \\
\text { solids and soils }\end{array}$ & 47 & 2 & 31 & 13 \\
Debris & 46 & 2 & 38 & 2 \\
Unique & 2 & 7 & & 55 \\
\hline Totals & 100 & & & \\
\hline
\end{tabular}

\section{GENERAL FINDINGS AND RECOMMENDATIONS}

The committee's primary recommendation is that MWFA should no longer emphasize the development of new classes of waste forms; rather, MWFA should now emphasize engineering design, integration, and scale-up of its proposed treatment processes and their 
demonstration and deployment at DOE sites. After reviewing the technologies available to treat EM's mixed waste inventory, and considering the resulting waste forms, it is the committee's judgment that no new classes of waste forms are required. Clearly, no single form is appropriate for all wastes, but collectively the variety of available waste forms and well-established waste form production technologies make it unlikely that any totally new class of waste forms will be necessary to complete EM's planned cleanup program.

Technology development and deployment must be cost-effective and commensurate with EM waste management strategy described in "Paths to Closure" (DOE, 1998c)(2). Secondly, MWFA should also focus attention on the long term characteristics of the current final waste forms, and take into account the quality of implementation of the treatment technology and the behaviour of the final waste form in realistic disposal conditions.

Thirdly, the committee recommends that MWFA should continue its practice of identifying, prioritizing, and responding to technology deficiencies. The MWFA has established a rational and systematic program that identifies and prioritizes deficiencies. The committee compliments MWFA on this effort.

Finally, the committee recommends that MWFA should broaden its use of the systems approach, in selecting, developing, and deploying technologies. Such an approach would begin with upfront characterization of the waste (development of cost-effective and efficiënt methods) and definition of the required performance of a proposed treatment technology, based on EM's needs, regulatory requirements, and stakeholder expectations. The basis for this recommendation is in the fact that all steps of waste management are closely interconnected, starting with the waste generation processes, characterization of raw wastes before they enter the long circuit of (long) interim storage, treatment, other interim storage, transportation, disposal. It may be difficult even to make an attempt at optimization if the major steps of the management system are not defined beforehand. Using its technical and managerial resources, MWFA should develop and assist in the design, development, and deployment of the new technology to ensure that the technology meets its performance goals. An important aspect of a good systems approach is flexibility to accomodate new information experiences and reasonable changes in the desired output. Inevitably there are iterations between the actual and the desired performance of any waste management system as its technology matures and expectations change.

In recommending that MWFA broadens its systems approach, the committee recognizes that the technical issues pertaining to waste management are often overshadowed by non-technical (e.g. political and social) issues. Public acceptance of a waste management strategy may be transient, which creates a moving target for engineers and programme planners. An example of these conflicts can be seen in the present study of currently available waste forms. The MWFA is developing and proposing technological methods to convert EM's "Paths to Closure" commitments. However, for many of the disposal sites that will receive mixed waste forms, waste acceptance criteria, and the actual disposal conditions for the waste forms are unspecified. A comprehensive systems approach must recognize these complicating, but real, factors.

\section{WASTE CHARACTERIZATION (upfront)}

The committee found that even if EM's mixed waste inventory may be sufficiently wellcharacterized for conceptual design of treatment processes, it is insufficiëntly 
characterized for detailed engineering design or process optimization. Detailed characterization, using currently available methods, will be expensive and may entail risks to operating personnel.

The committee has three recommendations:

1 The MWFA should develop simplified methods to characterize the waste inventory, with emphasis on nondestructive examination and nondestructive assay techniques. Emphasis should be placed on developing better methods to determine heavy metals and solvent contamination.

2. The MWFA should continue to develop, demonstrate and encourage deployment of techniques and procedures to ensure that all new waste streams are adequately characterized.

3. The MWFA should strive for a balance between the risks, benefits, and cost of detailed characterization and the effort and cost to develop more robust treatment technologies that can handle a wider variety of waste compositions, thus reducing the required degree of waste characterization.

There are two possible pathways to reduce costs and risks for which R\&D would be valuable. The first is for simplified methods of examining and characterizing wastes through such vehicles as rapid scanning, non-intrusive identification of constituents. The other pathway is through development of robust treatment technologies that can adequately deal with a variety of feed materials, thereby reducing the need for extensive characterization. The committee noted that the MWFA's recent experience in developing "universal" treatment technologies, such as the plasma torch, showed that these technologies still require adjustment according to waste composition. The committee therefore emphasizes the importance of waste characterization and encourages the MWFA to seek a reasonable balance in the development of characterization and treatment technologies.

The committee recognizes the difficulties in determining the composition of mixed waste when the waste is stored in many forms or in sealed containers. Detection and determination of some of the radioactive constituents by non-intrusive means is readily accomplished. Similar detection of "silent" hazardous materials such as toxic organic compounds and metals or characteristic waste components that could pose processing problems during the generation of acceptable waste forms continues to represent a major theoretical and practical challenge. The latter issue is of particular importance when mixed wastes also contain TRUs because the latter hinder inspection. The committee believes research efforts devoted to this problem could pay significant dividends, particularly in reducing the quantity of waste that must be treated as mixed waste that is, waste minimization. However, the committee also believes that the development of robust and comprehensive processing techniques that are insensitive to waste composition and yield satisfactory waste forms when the feed to the process is only poorly characterized should also be pursued.

\section{TREATMENT TECHNOLOGIES}

In its Technical Baseline Report (6), MWFA has drawn up process diagrams that conceptualize treatment for the majority of its varied waste streams. This effort has defined potential treatment systems and their final waste forms to meet the present regulations 
governing mixed wastes. In addition, volume reduction, cost reduction, and suitability for transportation are also objectives of the work.

The committee found that there are ample treatment technologies and waste forms for EM's mixed waste inventory. However, many of these technologies have not been demonstrated as part of an integrated production-scale system using actual wastes.

The committee has four recommendations:

1. MWFA should integrate treatment technologies for its five treatment groups (waste waters, combustible organics,inorganic homogeneous solids and soils, debris, unique wastes) into a mixed waste treatment strategy. This strategy should consider the waste form as part of an overall mixed waste management system that includes the following:

- compatibility of waste form with transportation and disposal options,

- trade-offs between risks to personnel associated with additional waste characterization and additional costs of a more robust treatment and stabilization system, and trade-offs between the increased number of disposal options for a very stable waste form, versus the lower costs but reduced disposal options for less stable waste forms.

2. MWFA should demonstrate new treatment technologies on at least the pilot plant scale using real wastes or realistic surrogates before the technology is designated as ready for deployment.

3. MWFA should continue to address technology deficiencies that it has identified through input from the Site Technology Coordinating Groups and update its Technical Baseline Report to reflect progress in addressing these deficiencies.

4. MWFA should continue to provide research funding for developing robust processes that can treat and stabilize waste of poorly defined or variable composition, recognizing the trade-off between better waste characterization and development of improved treatment technology.

The need for a treatment strategy follows from the committee's overall recommendation that MWFA adopt a more complete systems approach to its technology development, and from the committee's recognition of the trade-offs between the difficulties of developing broadly targeted, robust treatment technologies, and the potential risks to operators in sampling and analyzing the many and varied wastes that comprise the inventory. Trade-offs between grout and higher quality vitreous forms that are generally harder to make, are also recognized by the committee. The committee noted that the present plan for the privatized Advanced Mixed Waste Treatment Project is to produce grout forms, whereas early presentations by MWFA indicated that glass forms would also be produced.

The necessary technology demonstrations that are being planned at several DOE sites will inevitably be constrained by time and budgets. Such constraints can set the stage for later technology failures if larger scale testing is not done with careful planning, care, and diligence. For example, process steps should be thoroughly tested and evaluated before any radioactive materials enter a new facility. The final products should be extensively analyzed to avoid such issues as inadequate waste form performance because of unexpected variations in feedstock composition. The MWFA should play an important role as technology advisor during this very important demonstration phase. MWFA should also remain closely involved 
in the technology deployment phase to ensure successful technology transfer to the DOE sites or private contractors.

\section{AVAILABLE WASTE FORMS}

A wide variety of final waste forms is available for stabilizing the products of the processes. Selection of the most appropriate waste form for a waste stream at a DOE site is a key step in that site's overall waste management strategy. In identifying waste final forms for mixed waste, the MWFA has used the considerable experience in both the private sector and DOE. The literature contains many examples of waste forms that have been developed outside the MWFA for sanitary, hazardous, and low- and high-level radioactive waste that are also applicable to mixed waste $(7,8,9)$. The basic classes of waste forms include :

* grout,

* glass,

* polymers and bitumen,

* crystalline ceramics,

* vitreous ceramics,

* compacted wastes.

For most treated mixed wastes in the EM inventory, one or more of the above waste forms can meet the requirements of chemical durability, for example, leach resistance and long-term stability, physical strength and fracture resistance, and resistance to radiation damage $(10,11)$.

Compatibility with the waste stream is a primary consideration in selecting among the available waste forms; lack of compatibility limits the selection. Examples are:

incompatibility of organic liquids with grout, soluble inorganic salts may leach from grout as well as from polymers or bitumen. Compacted waste containing substantial amounts of paper, rubber gloves, etc., when placed in a disposal facility, may give rise to organic decay products, which, in turn, may increase the mobility of radioactive- and other hazardous mineral components.

\section{WASTE FORM CHARACTERIZATION AND PERFORMANCE ASSESSMENT}

To determine whether waste forms are sufficiently developed to stabilize EM's inventory of mixed waste, test protocols to characterize the waste forms must be available. The committee found no established tests that can demonstrate the long-term (greater than a few hundred years) behavior of a waste form; however, present methods are adequate to evaluate shortterm behavior. Committee findings include the following:

* the different regulatory approaches taken by EPA and USNRC, lead to different approaches to waste form testing. This is manifested by pass-fail waste form tests, such as the TCLP that are required by EPA, and other tests that provide data for performance assessment of the disposal system, as required by USNRC.

* the long-term behavior of a waste form in a disposal facility is difficult to assess because there is no agreed way to extrapolate laboratory tests designed for periods of days to years to behavior over hundreds of thousands of years. 
* OST should continue to support programs aimed at fundamental understanding of waste form durability and degradation processes. These programs should lead to a better representation of the waste form in PA modeling.

* OST should work with EPA and the USNRC to develop criteria for rapid testing protocols that can be used to determine whether a stabilized waste is suitable for disposal and to assist in quality assurance and quality control in the waste treatment and stabilization process. The objective of this rapid testing protocol would be to reduce the need for performing TCLP analyses on every batch of waste prior to its disposal.

* OST should work to promote consensus among EPA, USNRC, DOE, and the scientific community on waste form testing protocols that are generally acceptable for providing at least a qualitative evaluation of long-term waste form performance in disposal environments.

Performance assessment (PA) is required by the U.S. Regulatory Commission (USNRC) to evaluate the long-term safety of waste disposal facilities. The committee found that current PA methodology does not recognize the significance of the waste form or take reasonable credit for the waste form's ability to reduce the release rate of hazardous and radioactive constituents. This is mainly because of the lack of methods to quantify the long-term behavior of final waste forms.

The committee's four recommendations in the areas of waste form characterization and performance assessment are directed to OST because the recommendations apply to all DOE wastes:

1. OST should continue to support programs aimed at fundamental understanding of waste form durability and degradation processes. These programs should lead to a better representation of the waste form in PA modelling.

2. OST should work to promote consensus among the U.S. Environmental Protection Agency (USEPA), USNRC, DOE, and the scientific community on waste form testing methods that will be generally acceptable for providing at least a qualitative evaluation of long-term waste form performance in disposal environments.

3. OST should support efforts to obtain data that will allow a more realistic inclusion of waste forms in PA models, including inadvertent intrusion scenarios. Without such data the waste form might never receive proper credit in PA with the resulting cost penalties for additional engineered barriers and possible restriction in site selection.

4. OST should play a more significant role in promoting (funding) cooperation among investigators who are characterizing waste forms and those who are developing PA models to help ensure that characterization data are useful for PA models, and that PA models properly incorporate these data.

The credibility of performance assessments can be enhanced by better representation of waste form behavior in the disposal environment. More realistic assessments might allow more effective use of the capacity of disposal facilities by allowing them to accept a larger inventory of radionuclides or hazardous wastes. The EM Science Program (12) could provide a valuable mechanism for evaluating and funding research proposals for the fundamental studies recommended by the committee. 


\section{REGULATORY GUIDELINES}

The lack of available, licensed disposal sites for mixed wastes and uncertainties in the waste acceptance criteria of future sites introduce a significant risk in judging the adequacy of EM's planned mixed waste treatments and waste forms. The committee recommends that EM work with EPA and USNRC to agree on clear guidelines that describe acceptable waste forms for disposal of mixed waste in future near-surface disposal facilities. This should be done as soon as possible to reduce the risk of EM deploying technologies that are later judged inadequate because of unanticipated regulatory requirements.

\section{COMMITTEE ON MIXED WASTES}

Paul A. Dejonghe, chair, Study Centre for Nuclear Research (retired), Mol, Belgium Ann N. Clarke, ANC Associates, Inc., Brentwood, Tennessee Jurgen H. Exner, JHE Technology Systems, Inc., Alamo, California Kent F. Hansen, Massachusetts Institute of Technology, Cambridge Joann S. Lighty, University of Utah, Salt Lake City Richard J. Samelson, Consultant, Pittsburgh, Pennsylvania Martin J. Steindler, Argonne National Laboratory (retired), Argonne, Illinois Bruce M. Thomson, University of New Mexico, Albuquerque

\section{Staff}

John R. Wiley, Senior Staff Officer BRWM (January 1998 to end of study) Karyanil Thomas, Senior Staff Officer BRWM ( through December 1997) Angela R. Taylor, Senior Project Assistant, BRWM Laura D. Llanos Project Assistant, BRWM

\section{REFERENCES}

1. National Research Council. 1999. "The State of Development of Waste Forms for Mixed Wastes". Committee on Mixed Wastes. Board on Radioactive Waste Management. Washington, D.C., June 1999. National Academy Press.

2. U.S. Department of Energy. 1998c. Accelerating Cleanup: Paths to Closure. DOE/EM- 0362. Washington, D.C., June 1998.

3. National Research Council. 1996c. "Environmental Management Technology Development Program at the Department of Energy, 1995 Review". Wahington, D.C.: National Academy Press.

4. U.S. Department of Energy (DOE). 1995a. "The DOE National 1995 Mixed Waste Inventory Report". Internet http://www.em.doe.gov/ffcab/ffcaftp/index.htlm. January 1999.

5. $\quad$ U.S. Department of Energy. 1997a."Mixed Waste Focus Area Technical Baseline Report" DOE/ID-10524. Vols. 1 and 2. Idaho Falls,Id April 1997.

6. U.S. Department of Energy. 1996a. "Mixed Waste Focus Area Integrated Technical Baseline Report". DOE/ID-10524. Vols 1 and 2. Idaho Falls , January 1996.

7. Perret, D. 1998. "Municipal Solid Waste (MSW) Glasses: The Opinion of Selected Experts." Report 2. Swiss Agency for Environment, Forests and Landscape. October 1998. 
8. Lutze, W., and R.C. Ewing (Eds). 1998 "Radioactive Waste Forms for the Future".North Holland Physics Publishing.

9. Donald, I.W. , B.L. Metcalfe, and R.N.J. Taylor. 1997. "Review: The Immobilization of High Level Radioactive Wastes Using Ceramics and Glasses". Journal of MaterialsScience. 32:887.

10. Mayberry, J.L., and T.L. Huebner. 1993. "Technical Area Status Report for Low-level Mixed Waste Final Waste Forms". DOE/MWIP-3. Idaho Falls, Id: Science Applications International Corporation.

11. Ewing,R.C. and M.J. Jercinovic. 1987. "Natural Analogues: Their Application to the Prediction of the Long-Term Behavior of Nuclear Waste Forms. In Scientific Basis for Nuclear Waste Management. X.J.K. Bates and W.B. Seefeldt (Eds.). Materials Research Society. Proceedings. 84: 67-86. Pittsburgh,Pa.

12. National Research Council. 1997. Building an Effective Environmental Management Science Program: Final Assessment. Washington, D.C.: National Academy Press. 